\title{
Comparison of Single and Three phase Dynamic Charging Systems for Electric Vehicles
}

\author{
Van-Binh $\mathrm{Vu}$ \\ School of Engineering \\ Newcastle University \\ Newcastle upon Tyne, UK \\ v.b.vu2@ncl.ac.uk
}

\author{
Mohamed Dahidah \\ School of Engineering \\ Newcastle University \\ Newcastle upon Tyne, UK \\ mohamed.dahidah@ncl.ac.uk
}

\author{
Volker Pickert \\ School of Engineering \\ Newcastle University \\ Newcastle upon Tyne, UK \\ volker.pickert@ncl.ac.uk
}

\author{
Van-Tung Phan \\ School of Engineering \\ Newcastle University \\ Newcastle upon Tyne, UK \\ vantung.phan@ncl.ac.uk
}

\begin{abstract}
The main drawbacks of the single-phase system is the fluctuation of output power when receiver is in motion along the driving direction. This paper presents a three-phase wireless dynamic charging (WDC) for Electric Vehicles to address the above problem. The proposed three-phase system utilizes three windings in primary side that guarantees a homogeneous mutual magnetic flux for the receiver. Performance comparison between the single-phase and three-phase systems has carried out. An optimization analysis using Maxwell 3D simulation for both transmitter and receiver is conducted to achieve the highest coupling factor with a minimum ferrite. The effectiveness of the proposed system is analytically demonstrated and experimentally verified by experimental results.
\end{abstract}

Keywords- Dynamic Wireless Charging, Inductive Power Transfer, Electric Vehicle Battery Charger, Constant Output Power.

\section{INTRODUCTION}

The concept of WDC has been proposed in [1] for Electric Vehicles to overcome the limitation of current battery technology, which limits the high penetration of EVs. WDC enables EV to be charged wirelessly while in motion. As a result, the battery size of EVs can be greatly reduced and the driving range limitation can be completely alleviated. WDC is commonly developed based on inductive power transfer (IPT) technology, where a time varying magnetic field is generated by transmitter coils; which are installed underneath road surface, to wirelessly power receiver coils, which charging the EV's battery continuously [2]-[4].

A WDC can be categorized into short-track transmitters [57] or long-track transmitter [8-10] according to the length of transmitter coils. In the short-track transmitters, when the EV's receiver is in align with a specific transmitter, then the power switch connects the associated inverter to the transmitter. Therefore short-track type has advantageous of low electromagnetic field level and high efficiency as minimizing conduction loss on transmitter winding. However, the high implemented cost and system complexity are main downsides of short-track transmitter.

On the other hand, long-track transmitter [8-10] is much longer than the EV's length and only requires a single power inverter with one compensation tank. This brings benefits in terms of cost and simplicity for implementation of such a system. However, the efficiency is reduced and electromagnetic interference (EMI) is increased. Several studies are conducted to address EMI problem and also to simplify the structure of the system [11-13] by adopting alternative magnetic polarity to construct transmitters. Nevertheless, these studies also pointed out that the magnetic flux density generated by a single transmitter on a receiver varies in a nearly sinusoidal function depending on receiver's position along the driving direction. Consequently, the induced voltage and received power of the single-phase system are significantly pulsated depending on EV's position.

This paper firstly introduces a three-phase WDC system based on [14] to achieve a constant output power when EV is in motion within the driving direction. Next, the design consideration of both conventional single-phase and threephase system are presented and compared. Both systems utilize the same magnetic core structure but different number windings. An optimization of magnetic coupler is conducted so that the highest coupling coefficient can be achieved with a minimum copper cable and ferrite. Performances of these two systems are compared as well in term of output power and efficiency. A scale down laboratory prototype of 1-kW and $3-\mathrm{kW}$ are developed for the single and three-phase respectively to experimentally verify the feasibility and effectiveness of the proposed system.

\section{The Single AND THREE-PHASE WDC}

The layouts of both single-phase and three-phase systems are presented in Fig. 1 in which both systems utilize the same magnetic core structure. The transmitters system is constructed using multiple I-pole-type magnetic poles [11] with different polarities combining with three different windings. The receiver covers three magnetic poles and is in motion along the transmitter. As a result, the spatial distribution of mutual inductance between receiver and transmitters can be expressed in Fig. 2.a for the single and in Fig. $2 b$ for the three phase system. Mutual inductance equations therefore can be depicted as (1) and (2) for single and three-phase system, respectively. In these equations, $M_{o}$ is maximum value and phase-shift between two adjacent phases is $2 \pi / 3$ while $x$ is receiver's displacement along the driving direction and $l_{o}$ is spatial periodic length of the transmitter.

$$
\begin{gathered}
M_{1 s}(x)=M_{o} \sin \left(\frac{2 \pi x}{l_{o}}\right) \\
\left\{\begin{array}{c}
M_{1 s}(x)=M_{o} \sin \left(\frac{2 \pi x}{l_{o}}\right) \\
M_{2 s}(x)=M_{o} \sin \left(\frac{2 \pi x}{l_{o}}-\frac{2 \pi}{3}\right) \\
M_{3 s}(x)=M_{o} \sin \left(\frac{2 \pi x}{l_{o}}-\frac{4 \pi}{3}\right)
\end{array}\right.
\end{gathered}
$$




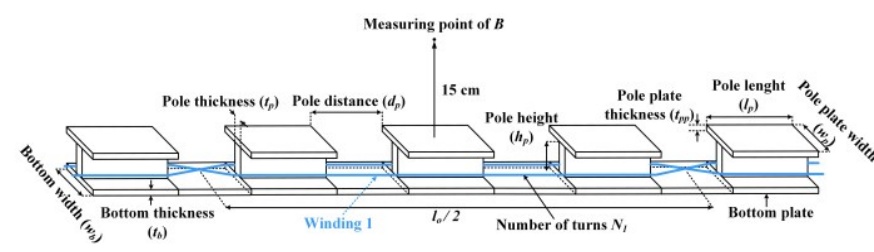

(a)

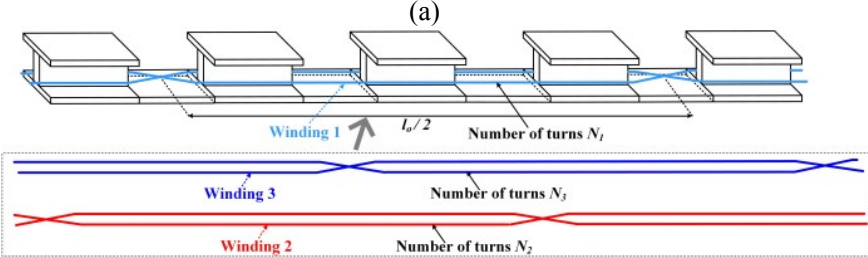

(b)

Fig. 1. Design parameters of primary transmitters (a) single-phase and (b) three-phase system

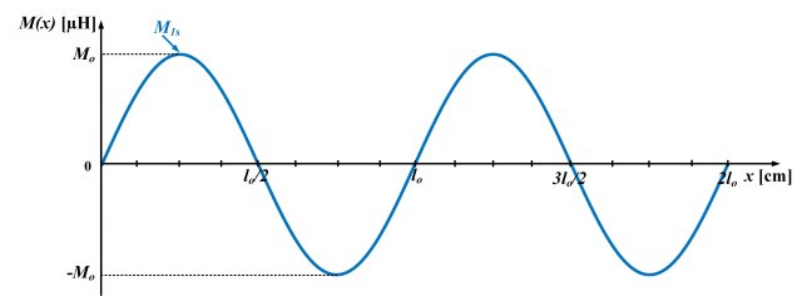

(a)

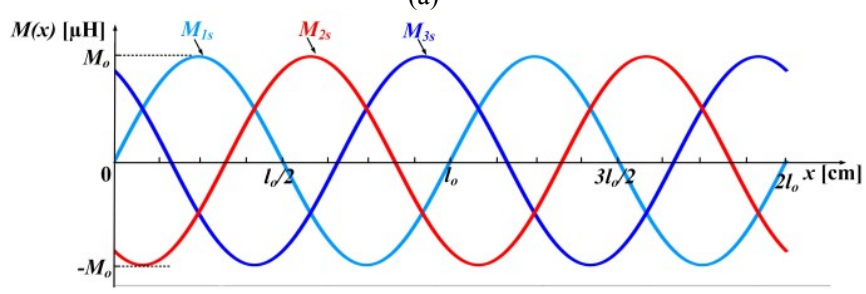

(b)

Fig. 2. Spatial distribution of mutual inductances of (a) single-phase and (b) three-phase transmitters system

The circuit configuration of both systems are showed in Fig. 3 . The switching frequency of primary inverter is selected as $85 \mathrm{kHz}$. For simplicity, the output battery is modelled as a resistive load $R_{o}$. For the single-phase system (i.e. Fig.3a), the single-phase full bridge is adopted in primary side to provide a constant high-frequency current $I_{p}$ to transmitter $L_{p}$ with the helps of a resonant tank LCC in primary side. The resonance between $L_{a}$ and $C_{a}$ is set at the switching frequency of the inverter. Transmitter structure is presented in Fig. 1a while the mutual inductance with receiver is showed in Fig. 2a. At the secondary side, another LCC resonant tank is connected with a full-bridge rectifier to provide DC power to the output load.

For three-phase system depicted in Fig. 3b, the three phase inverter is utilized. Primary side consists of 3 transmitters $L_{i}$ $(i=1,2,3)$ energizing one receiver coil, $L_{s}$. As mentioned before, three transmitters are arranged as Fig. $1 \mathrm{~b}$ to effectively produce a constant coupling magnetic flux between transmitters and receiver. As these transmitters are physically placed closed to each other, therefore crossing couplings $M_{12}$, $M_{13}, M_{23}$ exists between them as depicted in Fig. 3b. The mutual inductances between transmitter $L_{i}$ and receiver is denoted by $M_{i s}(i=1,2,3)$ while $M_{1 s}$ is of the conventional single-phase system and $M_{2 s}, M_{3 s}$ are additional inductances. Each transmitter is driven by a constant current source $I_{i}(i=$ $1,2,3)$ regardless of load and coupling coefficient conditions in which the phase-shift between two currents of two adjacent phases is $2 \pi / 3$ (i.e. 120 degree). The series capacitors $C_{i b}(i=$
$1,2,3)$ are used for resonating with the transmitter's inductance $L_{i a}$ and suppressing the induced voltages caused by the crossing couplings from other transmitters.

By applying Kirchhoff's law to models in Fig 2, the design equations of resonant tank for both systems are achieved and depicted in Table $I$ in which $\left|M_{12}\right|=\left|M_{13}\right|=\left|M_{23}\right|=$ $M_{\text {cross }}$. From experimental measurement, crossing mutual inductances $M_{12}, M_{13}$ and $M_{23}$ are all negative values that are approximately equal each other. It is noted that the design equations for secondary side tank is the same for both systems:

$$
\left\{\begin{array}{c}
\omega L_{1 s}-\frac{1}{\omega C_{2 s}}=0 \\
\omega L_{s}-\frac{1}{\omega C_{1 s}}-\frac{1}{\omega C_{2 s}}=0
\end{array}\right.
$$

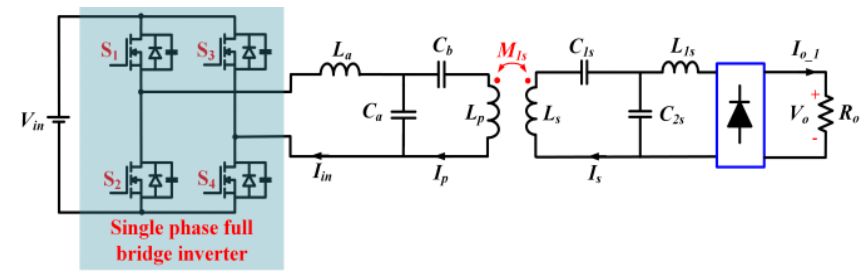

(a)

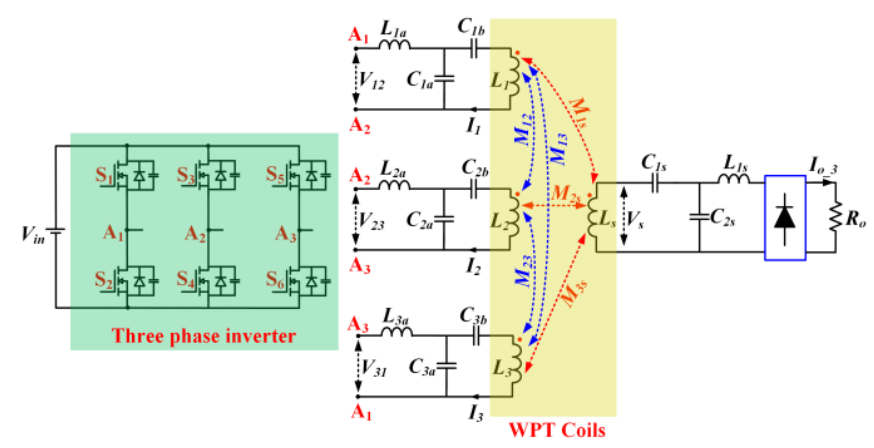

(b)

Fig. 3. (a) The conventional single-phase system (b) The proposed circuit of dynamic charging system with three transmitter coils.

TABLE I

Parameter Comparison OF Single AND Three Phase System

\begin{tabular}{|c|c|c|}
\hline & Single phase & Three phase \\
\hline $\begin{array}{l}\text { Series } \\
\text { Capacitor }\end{array}$ & $C_{b}=\frac{1}{\omega^{2}\left(L_{b}-L_{a}\right)}$ & $\begin{array}{l}C_{i b} \\
=\frac{1}{\omega^{2}\left(L_{i}-L_{i a}\right)}+\frac{1}{\omega^{2} M_{\text {cros }}} \\
\quad(i=1,2,3)\end{array}$ \\
\hline $\begin{array}{l}\text { Parallel } \\
\text { Capacitor }\end{array}$ & $C_{a}=\frac{1}{\omega^{2} L_{a}}$ & $\begin{aligned} C_{i a} & =\frac{1}{\omega^{2} L_{i a}} \\
(i & =1,2,3)\end{aligned}$ \\
\hline $\begin{array}{c}\text { Transmitter } \\
\text { Currents }\end{array}$ & $I_{p}=\frac{4}{\pi} V_{i n} \omega C_{a}$ & $\begin{array}{c}I_{i}=\frac{2 \sqrt{3}}{\pi} V_{i n} \omega C_{i a} \\
(i=1,2,3)\end{array}$ \\
\hline $\begin{array}{l}\text { Output } \\
\text { Current }\end{array}$ & $\begin{array}{l}I_{o_{-} 1} \\
=\frac{8}{\pi^{2}} \omega^{3} C_{a} C_{2 s} M_{1 s} V_{i n}\end{array}$ & $\begin{array}{c}I_{o_{-} 3}=\frac{6 \sqrt{3}}{\pi^{2}} \omega^{3} C_{i a} C_{2 s} M_{o} V_{i n} \\
(i=1,2,3)\end{array}$ \\
\hline $\begin{array}{l}\text { Output } \\
\text { Power }\end{array}$ & $P_{o_{-} 1}=\left(I_{o_{-} 1}\right)^{2} R_{o}$ & $P_{o_{-} 3}=\left(I_{o_{-} 3}\right)^{2} R_{o}$ \\
\hline
\end{tabular}


From Table I, it is clearly pointed out that output current $I_{o_{-} 1}$ and power $P_{o_{-} 1}$ of single phase system are sinuasoildal functions depending on EV's receiver displacement. On the other hand, the three phase system can guarantte a constant output power $P_{o_{-} 3}$ when receiver is in motion along the driving direction. Based on system requirements of input voltage, output current and power, therefore resonant tank should be designed properly according to the design equations presented in Table I.

\section{Optimized Design OF MAGNETIC COUPLER}

\section{A. Optimization of Transmitters}

This section presents the transmitters magnetic design aiming for maximum output power of $3 \mathrm{~kW}$. Both transmitters of single and three phase systems share the same magnetic core structure as shown in Fig. 1. For simplicity we consider only one winding in simulation model which is showed in Fig. 4a. Several simulations are conducted by MAXWELL 3D software to select the optimal parameters for transmitters, which are presented in Fig. 1. They consists of the ferrite pole sizes (thickness $t_{p}$, distance $d_{p}$, height $h_{p}$, length $l_{p}$ and plate width $w_{p}$ ), ferrite bottom sizes (width $w_{b}$ and thickness $t_{b}$ ) as well as number of transmitter's winding. The purpose of simulation is to determine the optimal parameters so that maximum of magnetic flux density $B$ can be attained at the center of every three poles (as shown in Fig. 3). With an appropriate receiver's design, maximum of $B$ also means maximum coupling coefficient $k$ and the highest power delivery as well as efficiency can be achieved as a result. Simultaneously, we try to minimize the ferrite core's volume and cable's length but the system still needs to satisfy the power delivery requirement and avoid the core's saturation. In order to produce a homogeneous magnetic flux along driving direction, number of turns should be selected equally for three windings (for three phase system) and all three transmitter's currents are set as maximum as $20 \mathrm{~A}$. The maximum air-gap between transmitter and receiver are selected as $15 \mathrm{~cm}$.

Thickness and width of pole and bottom plates are selected to prevent saturation problems. However, thickness values have very limited effect again magnetic fields. Fig. $4 \mathrm{~b}$ presents distribution of magnetic flux on ferrite core with bottom thickness $\left(t_{b}\right)=$ pole plate thickness $\left(t_{p p}\right)=0.5 \mathrm{~cm}$ and pole thickness $\left(t_{p}\right)=1.5 \mathrm{~cm}$. According to that the maximum magnetic flux density of $0.152 \mathrm{~T}$ occurs around the crossing winding areas on the core bottom. In this work, the ferrite core of PC47 by TDK Electronics is selected and their saturated magnetic flux density $B_{s}$ is founded as $0.54 \mathrm{~T}$ at $25^{\circ} \mathrm{C}$ [15]. Therefore, it is guaranteed of no saturation for primary core with output power level of $3 \mathrm{~kW}$ and transmitter current of 20 A. The widths of both bottom and pole plate are selected as 12 $\mathrm{cm}$.

It is remained other three parameters which need to determine: pole distance $\left(d_{p}\right)$, pole length $\left(l_{p}\right)$ and number of turns $(N)$. The relationship between $d_{p}$ and $l_{p}$ can be expressed as $d_{p}+l_{p}=l_{o} / 6$ with $l_{o}$ is fixed based on system's requirements, which is 2.4 meters in this work. Fig. 4c presents the relationship between normalized magnetic coupling against pole distance $d_{p}$. When $d_{p}$ varies in a range from 5 to $22.5 \mathrm{~cm}$, then normalized value of magnetic flux density reduces accordingly. It can be seen that the maximum magnetic flux density value can be achieved when pole distance at small values, from 5 to $7.5 \mathrm{~cm}$. This fact can be explained by deriving the magnetic flux equations depending winding's width and length [16]. Value $d_{p}$ of $7.5 \mathrm{~cm}$ is selected in this work because $5-\mathrm{cm}$ value creates a small space which may not enough to implement a large number of winding turns.

Fig. $4 \mathrm{~d}$ demonstrates how magnetic flux density $B_{l}$ varies according to number of turns for one single winding $N_{l}$. Theoretically, $B_{l}$ becomes linear with $N_{l}$ and while number of turns increases from 2 to 6 , then $B_{1}$ rises from 31 to $93 \mu \mathrm{T}$ as a result. Higher number of turns, higher power delivery capability, however, it also increases total copper wire's length, transmitter inductance and EMI to pedestrians. A number of 4 turns is finally selected and Litz wire (600 strands-AWG 38) is adopted to reduce conduction losses on windings. After several trial and errors in both simulations and experiments then final parameters are selected and depicted in TABLE II to meet with system requirements.

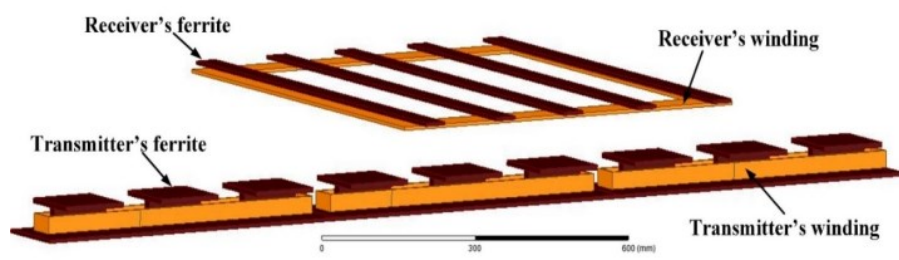

(a)

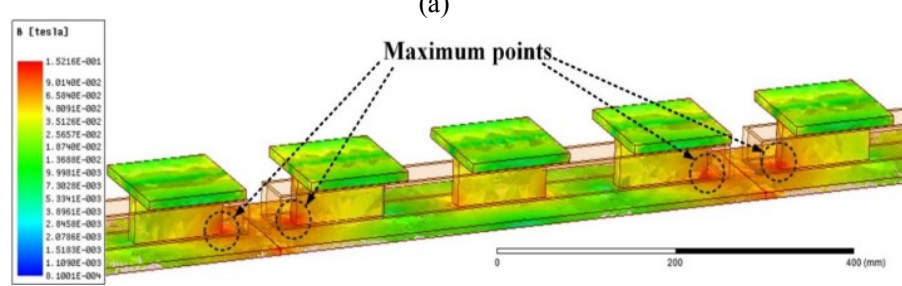

(b)

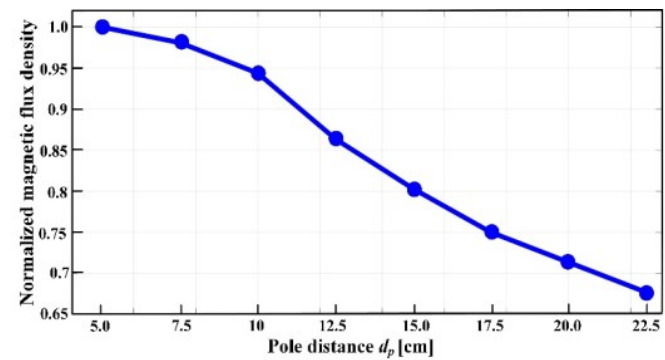

(c)

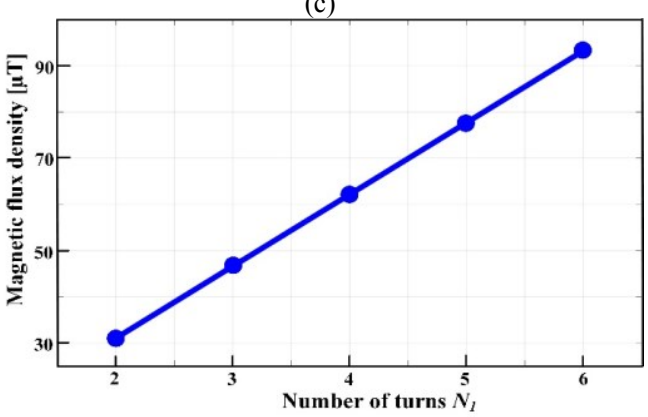

(d)

Fig. 4. (a) Simulation model of the proposed transmitters with $t_{b}, w_{b}, t_{p}, h_{p}, l_{p}$, $w_{p}, t_{p p}$ showing in Table II. (b) Contribution of magnetic flux density on transmitter's ferrite core with $N_{l} I_{l}=80 \mathrm{~A}$ (c) Normalized magnetic flux density depending on the pole distance with $N_{I} I_{I}=80$ A (d) Magnetic flux density depending on number of turns with $d_{p}=7.5 \mathrm{~cm}$. 
TABLE II

PARAMETER VALUES OF PRIMARY TRANSMITTERS

\begin{tabular}{|c|c|c|}
\hline$t_{b}$ & Bottom thickness & $0.5 \mathrm{~cm}$ \\
\hline$w_{b}$ & Bottom width & $12 \mathrm{~cm}$ \\
\hline$t_{p}$ & Pole thickness & $1.5 \mathrm{~cm}$ \\
\hline$d_{p}$ & Pole distance & $7.5 \mathrm{~cm}$ \\
\hline$h_{p}$ & Pole height & $4 \mathrm{~cm}$ \\
\hline$l_{p}$ & Pole length & $12 \mathrm{~cm}$ \\
\hline$w_{p}$ & Pole plate width & $12 \mathrm{~cm}$ \\
\hline$t_{p p}$ & Pole plate thickness & $0.5 \mathrm{~cm}$ \\
\hline$d$ & Air gap & $15 \mathrm{~cm}$ \\
\hline$N_{l}, N_{2}, N_{3}$ & Number of turns for each winding & 4 \\
\hline $2 l_{o}$ & Total transmitter's length & $2.4 \mathrm{~meters}$ \\
\hline
\end{tabular}

\section{B. Optimization of Receiver}

After obtaining transmitter's parameters, this section provides the design for receiver's parameters, which include receiver's length $l_{r}$, width $w_{r}$ and number of turns $N_{s}$. The most sensitive parameter as regards the coupling coefficient $k$ is the receiver's length $l_{r}$. Fig. 5a shows result of how coupling coefficient against $l_{r}$ with transmitter parameters on Table I. As shown in Fig. 5a, normalized coupling value increases from 0.05 at $l_{r}=30 \mathrm{~cm}$ and reaches to the highest value when $l_{r}=60 \mathrm{~cm}$ (equal to $l_{o} / 2$ ). If $l_{r}$ goes higher than 60 $\mathrm{cm}$, then $k$ drops significantly to nearly zero at $100 \mathrm{~cm}$. It can be explained by the fact that when $l_{r}<60 \mathrm{~cm}$, then receiver's winding cannot cover entirely the align transmitter winding, therefore, $k$ is always lower than the highest value. For $l_{r}>60$ $\mathrm{cm}$, then receiver is also received magnetic fluxes from other two adjacent transmitter windings which have reversed current directions and create opposite magnetic fluxes as compared to the align winding. Totally, there is a flux reduction on receiver when $l_{r}>60 \mathrm{~cm}$ as compared to the highest case. More seriously, the total flux on receiver can be cancelled completely if the total flux coming in equals to the flux coming out receiver. It results in no coupling between two sides and no induced voltage in the receiver winding.

Fig. $5 \mathrm{~b}$ and $5 \mathrm{c}$ provides simulation results of coupling coefficient under different receiver's width and lateral misalignments values. Value of $k$ needs to be high as much as possible at different lateral misalignment conditions. Fig. 5b provides coupling values regarding different receiver's width $w_{r}$ under no misalignment. It shows that $k$ increases from 0.062 to nearly 0.1 when $w_{r}$ rises from 10 to $30 \mathrm{~cm}$. However, if $w_{r}$ continues to increases up to $70 \mathrm{~cm}$ then $k$ will slightly reduce. Under lateral misalignment conditions, it can be investigated in Fig. 5c that how reduction of coupling regarding different receiver's width values. If misalignment level equals to $30 \mathrm{~cm}$, then $k$ will reduce to nearly $0 \%, 30 \%$ and $60 \%$ associating with $w_{r}=50,60$ and $70 \mathrm{~cm}$, respectively. Fundamentally, higher $w_{r}$ values enhances coupling and output power under lateral misalignment, however, $k$ also reduces when increasing $w_{r}$ at perfect align condition. Moreover, $w_{r}$ is also limited by installation space at bottom of vehicle. Considering all above factors, $w_{r}$ is selected as $60 \mathrm{~cm}$ in this work so that output power level can remain at $30 \%$ of maximum power under $30 \mathrm{~cm}$ of lateral misalignment. After selecting receiver's dimensions of $l_{r}=w_{r}$ $=60 \mathrm{~cm}$, then number of turns $N_{s}$ can be estimated as 8 turns based on the required output voltage (i.e. $450 \mathrm{~V}$ ) and operating frequency (i.e. $85 \mathrm{kHz}$ ).

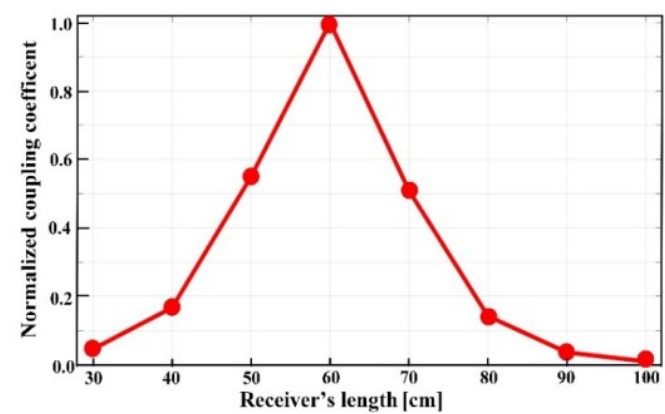

(a)

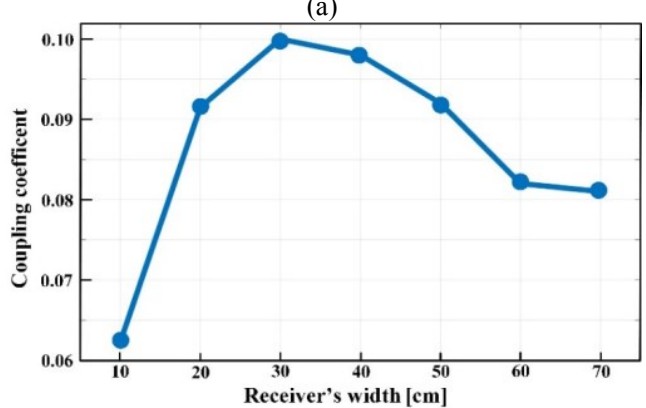

(b)

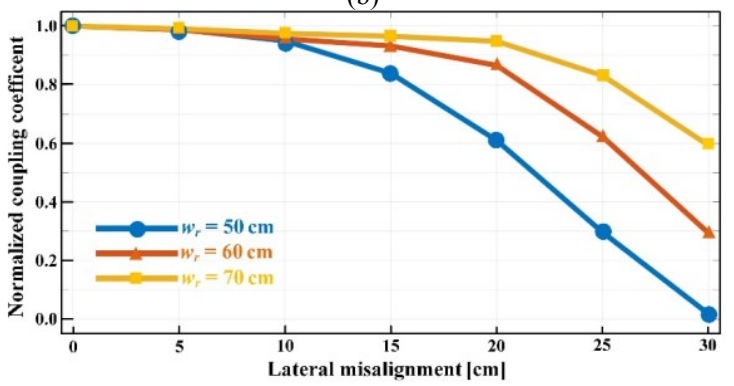

(c)

Fig. 5. Simulation on Maxwell 3D of normalized coupling coefficient with transmitter's parameters from Table I against (a) different receiver's length $l_{r}$ (b) different receiver's width $w_{r}$ at no misalignment (c) different lateral misalignment conditions.

\section{EXPERIMENTAL VERIFICATION}

The laboratory prototype of $3-\mathrm{kW}$ WDC is implemented and tested to validate the design procedure in previous Sections. The parameters of transmitters and receiver are mentioned in Sessions III. A 2.4-meter-long transmitters system is built up for both single and three phase systems as shown in Fig. 6a and 6b, respectively while the receiver is shown in Fig. 6c. For three phase system, three windings are arranged in three different layers, which isolates from each other by using plastic sheets. The detailed system specification is depicted in Table III.

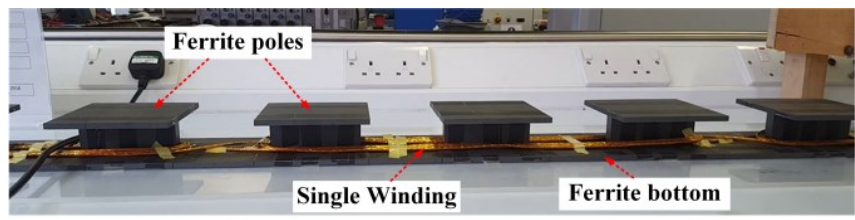

(a) 


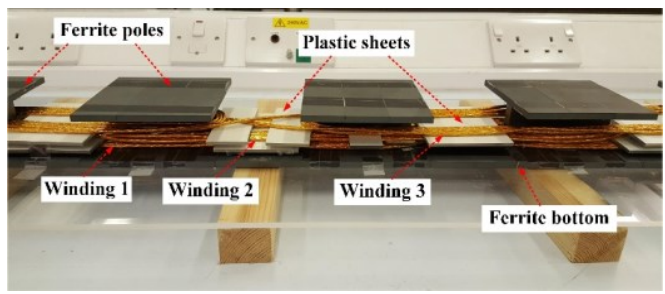

(b)

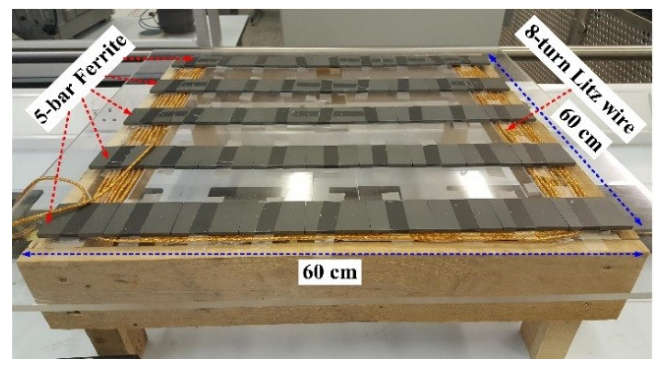

(c)

Fig. 6. Experimental test-rig of the three-phase WDC system (a) Singlephase transmitter (b) Three-phase transmitters (c) Receiver

TABLE III

SPECIFICATION AND PARAMETERS OF TWO WDC SYSTEMS

\begin{tabular}{|c|c|c|}
\hline Symbol & Parameter & Value \\
\hline$V_{\text {in }}$ & Input voltage & $400 \mathrm{~V}$ \\
\hline$I_{o}$ & Rated output current & $6.5 \mathrm{~A}$ \\
\hline$P_{o}$ & Rated output power & $3 \mathrm{~kW}$ \\
\hline$L_{p}, L_{1}, L_{2}, L_{3}$ & Self-inductance of transmitters & $182 \mu \mathrm{H}$ \\
\hline$L_{s}$ & Self-inductance of receiver & $118 \mu \mathrm{H}$ \\
\hline$M_{o}$ & Maximum mutual inductance & $12.5 \mu \mathrm{H}$ \\
\hline$M_{12}, M_{13}, M_{23}$ & $\begin{array}{c}\text { Crossing mutual inductances } \\
\text { (three-phase system) }\end{array}$ & $-46 \mu \mathrm{H}$ \\
\hline$L_{a}, L_{1 a}, L_{2 a}, L_{3 a}$ & Primary additional inductors & $37 \mu \mathrm{H}$ \\
\hline$C_{a}, C_{1 a}, C_{2 a}, C_{3 a}$ & Primary parallel capacitors & $95 \mathrm{nF}$ \\
\hline$C_{b}$ & $\begin{array}{l}\text { Primary series capacitors } \\
\text { (single-phase system) }\end{array}$ & $24.2 \mathrm{nF}$ \\
\hline$C_{1 b}, C_{2 b}, C_{3 b}$ & $\begin{array}{c}\text { Primary series capacitors } \\
\text { (three-phase system) }\end{array}$ & $100.4 \mathrm{nF}$ \\
\hline $\bar{L} L_{1 s}$ & Secondary additional inductors & $35 \mu \mathrm{H}$ \\
\hline$C_{2 s}$ & Secondary parallel capacitors & $100 \mathrm{nF}$ \\
\hline$C_{l s}$ & Secondary series capacitors & $42.2 \mathrm{nF}$ \\
\hline$f$ & Switching frequency & $85 \mathrm{kHz}$ \\
\hline
\end{tabular}

The key waveforms of the single-phase system are shown in Fig. 7 (i.e. load resistance $=40 \Omega$ ) while receiver is in the moving process along the driving direction from minimum- $>$ maximum-> minimum points of $M_{l s}$. It is clearly pointed out that the harvesting power of receiver is varied (representing by receiver's current $I_{s}$ in Fig. 7c) within moving process of receiver.

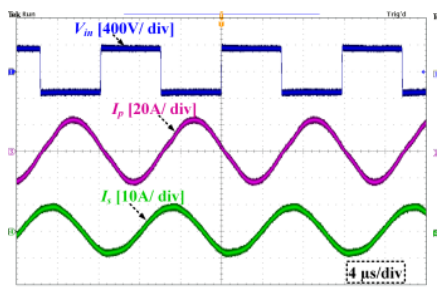

(a)

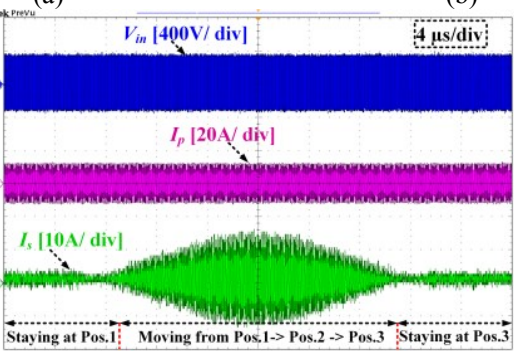

(c)

Fig. 7. Experimental waveforms of Single-phase system when receiver locates at (a) the highest value of $M_{l s}$, (b) the lowest value of $M_{l s}$ (c) receiver moving between: minimum (Pos.1) $->$ maximum (Pos.2) $->$ minimum (Pos.3) output power points.

Fig. 8 shows the key waveforms for three-phase system under different load resistances of $40 \Omega$ and $70 \Omega$. Inverter output voltages $V_{12}, V_{23}$ and $V_{31}$ can be seen in Fig. 8a while transmitter currents $I_{1}, I_{2}$ and $I_{3}$ in Fig. $8 \mathrm{~b}$ which have the same amplitude and a phase-shift of 120 degree between any two adjacent currents. On the contrary to single-phase system, the output power of three-phase system can be kept constant while receiver is in motions as depicted in Fig. 8c and 8d

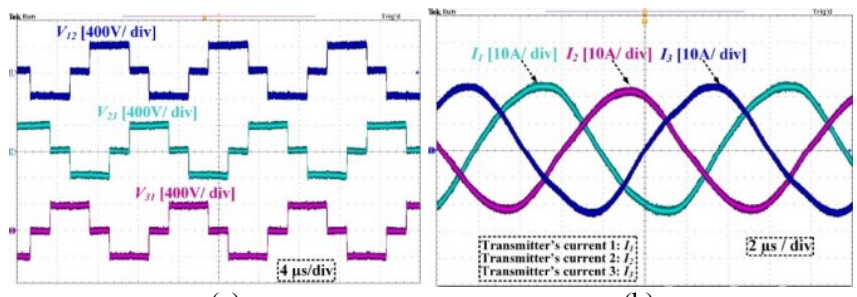

(a)

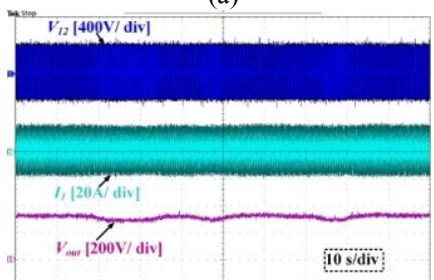

(c)

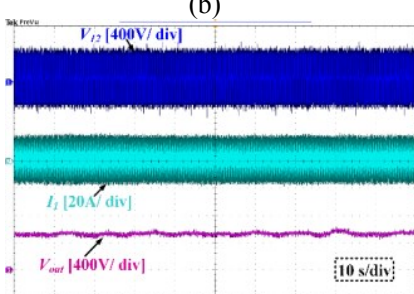

(d)
Fig. 8. Experimental waveforms of three-phase system (a) Primary inverter's voltage, (b) Transmitter's currents, while receiver moving along driving direction (c) $R_{o}=40 \Omega$, (d) $R_{o}=70 \Omega$

The spatial output power variation of two systems along the driving direction $x$ of transmitters are measured and compared in Fig 9. For single phase system (i.e. Fig. 9a), the output power is proportional with value of $\left|M_{1 s}\right|$ in which there are four points (i.e. $x=0,60,120,180$ and $240 \mathrm{~cm}$ ) where output power reaches nearly to zero. Fig. $9 \mathrm{~b}$ present spatial output power $P_{o}$ for three-phase system with different load resistances of 17,40 and $70 \Omega$. It is clearly shown that $P_{o}$ is constant regardless of receiver's displacement. When the load resistance increases, then output power increases accordingly as the output has a load-independent current feature. 

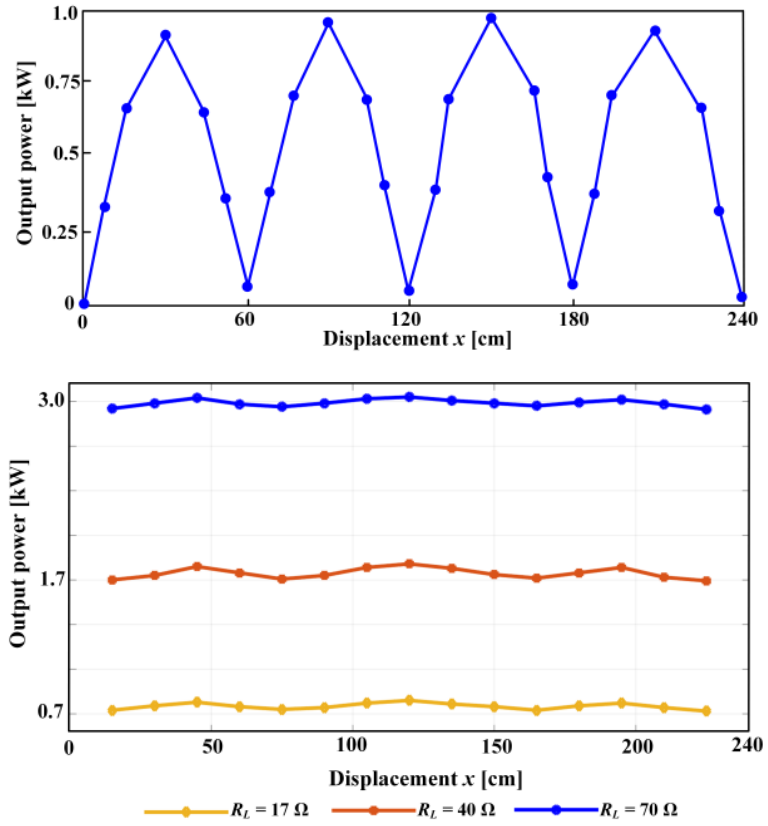

Fig. 9. Measured output power in various displacement of the receiver along driving direction and different load conditions (a) Single phase system with $1 \mathrm{~kW}$ output power (b) Three phase system with $3 \mathrm{~kW}$ output power

Fig. 10 compares the efficiency performance between two systems while receiver moves along the driving direction from displacement $x$ of $60 \mathrm{~cm}$ to $120 \mathrm{~cm}$. Resistive load is adjusted so that output powers are 1 and $3 \mathrm{~kW}$ for single and three-phase system, respectively. The results indicate that efficiency drops significantly to nearly zero in the singlephase system at the points of 60 and $120 \mathrm{~cm}$ (i.e. null-mutualinductance points). Efficiency then increases when receiver moves either from 70 to $90 \mathrm{~cm}$ or in reverse direction from 110 to $90 \mathrm{~cm}$ and reaches to maximum of $89.6 \%$ at $90 \mathrm{~cm}$. Differentiating from single-phase system, the proposed threephase offers a nearly constant efficiency along the driving direction as output power are kept unchanged when receiver moving. At the rated power of $3 \mathrm{~kW}$ then efficiency achieve around $87.8 \%$.

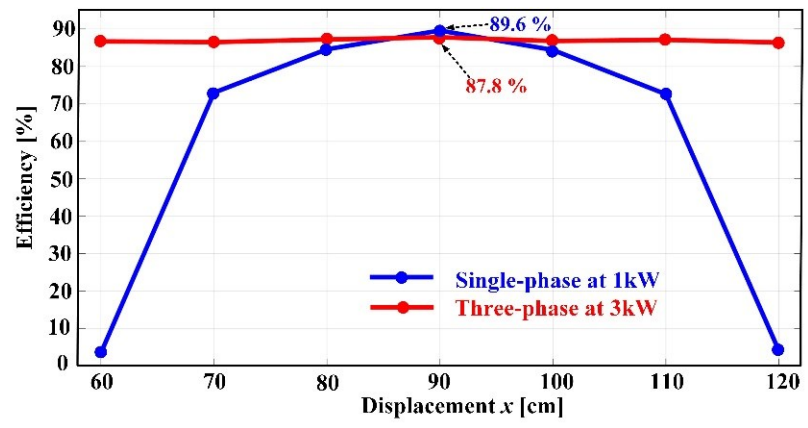

Fig. 10. Efficiency comparison between single-phase and three-phase system

\section{CONCLUSION}

This paper presented a three-phase WDC system for EVs aiming for achieving constant output power while receiver is in motions along driving direction. Next the comparison is made between the conventional single phase and the proposed three phase system in terms of design procedure, implementation and system performances.
Both systems utilize the same magnetic core shape and an optimization analysis using Maxwell 3D software is carried out to achieve the highest coupling factor with a minimum ferrite.

To validate the theoretical analysis, the laboratory prototype of two systems are built and tested under different operating conditions of load and receiver's displacement. The results show that high spatial power variation is occurred for the single phase system while three-phase system can attain a near constant output power under different load conditions.

\section{REFERENCES}

[1] S. Y. Choi , B. W. Gu , S. Y. Jeong, C. T. Rim "Advances in Wireless Power Transfer Systems for Roadway-Powered Electric Vehicles," IEEE J. Emerg. Sel. Topics Power Electron., vol. 3, no. 1, pp. 18-36, Mar. 2015.

[2] V. B. Vu, V. T. Doan, V. L. Pham, and W. J. Choi, "A new method to implement the constant current- constant voltage charge of the inductive power transfer system for electric vehicle applications," in Proc. IEEE Transp. Electrification Conf. Expo., Asia-Pac., Busan, South Korea, 2016, pp. 449-453.

[3] V. B. Vu, D. H. Tran and W. J. Choi, "Implementation of the Constant Current and Constant Voltage Charge of Inductive Power Transfer Systems with the Double-Sided LCC Compensation Topology for Electric Vehicle Battery Charge Applications," IEEE Trans. Power Electron., IEEE Trans. Power Electron., vol. 33, no. 9, pp. 7398 7410,Sep. 2018.

[4] V. B. Vu, V. T. Phan, M. Dahidah and V. Pickert, "Multiple Output Inductive Charger for Electric Vehicles," IEEE Trans. Power Electron., to appear.

[5] G. A. Covic and J. T. Boys, "Modern trends in inductive power transfer for transportation applications," IEEE Trans. Emerg. Sel. Topics Power Electron., vol. 1, no. 1, pp. 28-41, Mar. 2013.

[6] Q. Zhu, L. Wang, Y. Guo, C. Liao, and F. Li, "Applying LCC compensation network to dynamic wireless EV charging system," IEEE Trans. Ind. Electron., vol. 63, no. 10, pp. 6557-6567, Oct. 2016.

[7] J. M. Miller, O. C. Onar, C. P. White, and S. Campbell, "Demonstrating dynamic wireless charging of an electric vehicle: The benefit of electrochemical capacitor smoothing," IEEE Power Electron. Mag., vol. 1, no. 1, pp. 12-24, Mar. 2014

[8] J. Shin et al., "Design and implementation of shaped magnetic resonance based wireless power transfer system for roadway-powered moving electric vehicles," IEEE Trans. Ind. Electron., vol. 61, no. 3, pp. 1179-1192, Mar. 2014

[9] B.-M. Song, R. Kratz, and S. Gurol, "Contactless inductive power pickup system for Maglev applications," in Proc. 37th IEEE IAS Annu. Meeting, Oct. 13-18, 2002, vol. 3, pp. 1586-1591.

[10] W. Y. Lee et al., "Finite-width magnetic mirror models of mono and dual coils for wireless electric vehicles," IEEE Trans. Power Electron., vol. 28, no. 3, pp. 1413-1428, Mar. 2013.

[11] J. Huh, S. W. Lee, W. Y. Lee, G. H. Cho, and C. T. Rim, "Narrowwidth inductive power transfer system for on-line electrical vehicles (OLEV)," IEEE Trans. Power Electron., vol. 26, no. 12, pp. 3666 3679, Dec. 2011

[12] S. Y. Choi et al., "Ultraslim S-type power supply rails for roadwaypowered electric vehicles," IEEE Trans. Power Electron., vol. 30, no. 11, pp. 6456-6468, Nov. 2015.

[13] C. Park, S. Lee, S. Jeong, G.-H. Cho, and C. Rim, "Uniform power Itype inductive power transfer system with DQ-power supply rails for on-line electric vehicles," IEEE Trans. Power Electron., vol. 30, no. 11, pp. 6446-6455, Nov. 2015.

[14] V. B. Vu, M. Dahidah, V. Pickert and V. T. Phan, "A Concept of Multiphase Dynamic Charging System with Constant Output Power for Electric Vehicles," in Proc. IEEE PELS Workshop on Emerging Technology: Wireless Power (WoW), London, UK, Jun. 2018, to be published.

[15] [Online] Characteristics of Mn-Zn ferrite materials - TDK Product Center. Available: https://product.tdk.com

[16] M. Misakian, "Equations for the magnetic field produced by one or more rectangular loops of wire in the same plane," Journal of ResearchNational Institute of Standards And Technology, vol. 105, no. 4, July. 2000 . 